\title{
ПАРАКВАТНАЯ МОДЕЛЬ ПАРКИНСОНИЗМА И ВЫЯВЛЕНИЕ ФОСФОРИЛИРОВАННОГО $\alpha$-СИНУКЛЕИНА В ЭНТЕРАЛЬНОЙ НЕРВНОЙ СИСТЕМЕ У КРЫС
}

А. В. Ставровская $\bowtie$, Д. Н. Воронков, К. А. Кутукова, М. В. Иванов, А. С. Гущина, С. Н. Иллариошкин

Научный центр неврологии, Москва, Россия

Болезнь Паркинсона (БП) - распространенное нейродегенеративное заболевание с широким спектром моторных и немоторных нарушений. Немоторные симптомы (в частности, нарушения функций желудочно-кишечного тракта) обычно опережают манифестацию нарушений моторики на 5-15 лет. Характерный признак БП, цитоплазматические агрегаты фосфорилированного белка $\alpha$-синуклеина, обнаруживают не только в церебральных нейронах, но и в интрамуральных вегетативных сплетениях кишечника. В связи с этим большое значение имеет оценка периферического звена молекулярного патогенеза БП на экспериментальных моделях, в том числе при воздействии специфических «паркинсонических» нейротоксинов, таких как гербицид паракват. Целью работы было выявить комплекс ранних патологических изменений, вовлекающих $\alpha$-синуклеин, при системном многократном введении крысам параквата в дозе 6 мг/кг. У экспериментальных животных было показано снижение двигательной активности в открытом поле, двукратное (р = 0,044) одностороннее увеличение числа случаев соскальзывания в тесте «сужающаяся дорожка", снижение интенсивности окрашивания на тирозингидроксилазу (ТирГд) структур черной субстанции среднего мозга и нервных волокон миентерального сплетения кишечника крысы на 50\% (p = 0,033) и на 20\% (p = 0,01) соответственно, а также увеличение содержания фосфорилированного $\alpha$-синуклеина в телах миентеральных нейронов и в ТирГд-позитивных волокнах. Полученные изменения, свидетельствующие о развитии периферической $\alpha$-синуклеинопатии на ранней стадии экспериментального паркинсонизма, сходны с таковыми у пациентов в дебюте БП. Предложенный режим введения параквата может быть чрезвычайно перспективным в моделировании БП.

Ключевые слова: болезнь Паркинсона, моделирование на животных, $\alpha$-синуклеин, паракват, поведение, тирозингидроксилаза

Финансирование: работа поддержана грантом РНФ № 19-15-00320

Благодарности: авторы благодарят сотрудников лаборатории экспериментальной патологии нервной системы А. С. Ольшанского и Н. Г. Ямщикову за вклад в работу.

Информация о вкладе авторов: А. В. Ставровская — планирование исследования, анализ литературы, сбор, анализ и интерпретация данных, введение препаратов, проведение поведенческих тестов, подготовка черновика рукописи; Д. Н. Воронков - анализ литературы, анализ и интерпретация данных, подготовка и проведение морфохимического исследования образцов мозга экспериментальных крыс, подготовка черновика рукописи; К. А. Кутукова анализ литературы, анализ данных, подготовка и проведение морфохимического исследования образцов тонкого кишечника экспериментальных крыс, подготовка черновика рукописи; М.В.Иванов - подготовка и проведение морфохимического исследования образцов тонкого кишечника экспериментальных крыс; А. С. Гущина - сбор данных, введение препаратов, проведение поведенческих тестов, ветеринарное сопровождение исследования; С. Н. Иллариошкин - общее руководство исследованием, подготовка черновика рукописи.

Соблюдение этических стандартов: содержание животных и проведение экспериментов с ними осуществляли в соответствии с международными правилами «Guide for the Care and Use of Laboratory Animals»; исследование одобрено этическим комитетом ФГБНУ НЦН (протокол № 2-5/19 от 20 февраля 2019 г.).

$\triangle$ Для корреспонденции: Алла Вадимовна Ставровская пер. Обуха, д. 5, г. Москва, 103064; alla_stav@mail.ru

Статья получена: 12.08.2019 Статья принята к печати: 26.08.2019 Опубликована онлайн: 13.09.2019

DOI: 10.24075/vrgmu.2019.058

\section{PARAQUAT-INDUCED MODEL OF PARKINSON'S DISEASE AND DETECTION OF PHOSPHORYLATED $\alpha$-SYNUCLEIN IN THE ENTERIC NERVOUS SYSTEM OF RATS}

Stavrovskaya AV $\bowtie$, Voronkov DN, Kutukova KA, Ivanov MV, Gushchina AS, Illarioshkin SN

Research Center of Neurology, Moscow, Russia

Parkinson's disease (PD) is a common neurodegenerative disorder with a variety of motor and non-motor features. Non-motor symptoms, such as gastrointestinal dysfunction, usually set in 5 to 15 years earlier than motor manifestations. Cytoplasmic aggregates of phosphorylated $\alpha$-synuclein are a typical marker of PD. They are observed not only in cerebral neurons but also in intramural plexuses of the intestine. Therefore, it is essential to investigate the peripheral component of the molecular pathogenesis of the disease using PD models, including those involving the use of parkinsonian neurotoxins, such as the well-known herbicide paraquat. The aim of this study was to identify a complex of early $\alpha$-synuclein-related changes induced by long-term systemic administration of paraquat to rats at doses of $6 \mathrm{mg} / \mathrm{kg}$. The open-field test revealed a decline in the motor activity of the experimental animals; the tapered beam walking test demonstrated a two-fold increase $(p=0.044)$ in the number of left paw slips. Besides, the intensity of staining for tyrosine hydroxylase $(\mathrm{TH})$ in the substantia nigra and myenteric plexus fibers was 50\% ( $p=0.033)$ and $20 \%(p=0.01)$ lower, respectively, in the main group than in the controls. Phosphorylated $\alpha$-synuclein content was increased in the cell bodies of myenteric neurons and in TH-positive nervous fibers of the experimental animals. Changes indicating the development of peripheral $\alpha$-synuclein pathology in the early stage of induced PD are similar to the changes observed in patients with PD at the onset of the disease. The proposed paraquat regimen could be very promising for PD modeling.

Keywords: Parkinson's disease, animal models, $\alpha$-synuclein, paraquat, behavior, tyrosine hydroxylase

Funding: this work supported by the Russian Science Foundation (Grant 19-15-00320).

Acknowledgement: the authors thank their colleagues, Olshansky AS and Yamshchikova NG (the Laboratory of Experimental Pathology of the Nervous System), for their valuable contribution.

Author contribution: Stavrovskaya AV planned the study, analyzed the literature, collected, analyzed and interpreted the obtained data, conducted behavioral tests, administered drugs to the animals, and prepared the draft of the manuscript; Voronkov DN analyzed the literature, analyzed and interpreted the obtained data, prepared brain slides, conducted the histopathologic examination, and prepared the draft of the manuscript; Kutukova KA analyzed the literature, analyzed the obtained data, prepared jejunum slides, carried out the histopathologic examination, and prepared the draft of the manuscript; Ivanov MV prepared jejunum slides and carried out the histopathologic examination; Gushchina AS collected data, administered drugs to the rats, carried out behavioral tests, and monitored the animals' health as a vet; Illarioshkin SN supervised the study and prepared the draft of the manuscript.

Compliance with ethical standards: the animals were treated and the experiments were conducted in full compliance with the Guide for the Care and Use of Laboratory Animals; the study was approved by the Ethics Committee of Research Center of Neurology (Protocol № 2-5/19 dated February 20, 2019).

$\triangle$ Correspondence should be addressed: Alla V. Stavrovskaya per. Obukha, 5, Moscow, 103064; alla_stav@mail.ru

Received: 12.08.2019 Accepted: 26.08.2019 Published online: 13.09.2019

DOI: 10.24075/brsmu.2019.058 
Болезнь Паркинсона (БП) относится к числу наиболее распространенных неврологических расстройств, особенно у лиц старше 60 лет. Общее число пациентов с БП в мире составляет не менее 4 млн и, согласно прогнозам, может удвоиться к 2040 г. по мере увеличения доли пожилых людей в обществе [1]. Патогенетическое лечение БП не разработано, поэтому особое значение имеет изучение молекулярных механизмов заболевания, в том числе на модельных животных.

Характерные моторные симптомы БП (брадикинезия, мышечная ригидность, тремор покоя) обусловлены поражением дофамин-продуцирующих нейронов черной субстанции среднего мозга, дегенерацией нигростриатного дофаминергического пути и развивающимся нейротрансмиттерным дисбалансом в центральной нервной системе (ЦНС) [2]. У больных БП наблюдается также целый ряд немоторных клинических проявлений, самый частый из которых, дисфункция желудочно-кишечного тракта (констипация и др.), развивается задолго до манифестации первых моторных симптомов заболевания [3]. Нарушения со стороны желудочно-кишечного тракта при БП связывают с вовлечением в патологический процесс периферических отделов вегетативной нервной системы, однако до настоящего времени соответствующие пусковые механизмы и закономерности взаимодействия «периферического» и «центрального» звеньев патогенеза БП остаются не вполне ясными.

Основным молекулярным событием, приводящим к повреждению нейронов ЦНС при БП, считают нарушение конформации небольшого синаптического белка $\alpha$-синуклеина [4]. Именно агрегаты фосфорилированного $\alpha$-синуклеина в цитоплазме нейронов являются основным биохимическим субстратом телец Леви - классических патоморсоологических маркеров БП [2]. Интересно, что патологическую агрегацию $\alpha$-синуклеина обнаруживают не только в церебральных нейронах, но и в биопсийном и аутопсийном материалах интрамуральных вегетативных сплетений кишечника больных БП, в связи с чем выдвинуто предположение об энтеральных сплетениях как о первичном сайте патологического процесса, распространяющегося далее на структуры ЦНС через волокна блуждающего нерва [5]. Существуют данные о том, что триггерную роль в $\alpha$-синуклеиновом каскаде могут играть некоторые нейротоксины окружающей среды, такие как тяжелые металлы, пестициды и фунгициды $[6,7]$. Так, образование агрегатов $\alpha$-синуклеина и Левипатологии способен инициировать сильный гербицид неспецисьического действия паракват (1,1-диметил-4,4бипиридин), который широко используют для уничтожения сорняков во фруктовых садах, на пахотных землях сельскохозяйственного использования, плантациях кофе, какао, чая и т. д., а также в качестве высушивающего агента при переработке сельскохозяйственной продукции [6, 8, 9]. Его особенностью является структурное сходство с активным метаболитом известного нейротоксина, 1-метил-4-фенил-1,2,3,6-тетрагидропиридина (МФТП), токсичным катионом 1-метил-4-фенилпиридиния (МФП+), что позволяет использовать паракват для моделирования БП на животных. Токсичный эффект параквата связан с образованием супероксидных радикалов, но при этом он обладает низкой аффинностью к комплексу I дыхательной цепи митохондрий.

При моделировании БП обычно используют длительное системное введение параквата в дозе 10 мг/кг, что приводит к выраженным нарушениям движения экспериментальных животных и вызывает значительные дегенеративные изменения дофаминергических нейронов черной субстанции [10]. Однако такой подход не пригоден для изучения начальных стадий патологического процесса и оценки премоторных симптомов заболевания. Целью работы было выявить у крыс комплекс наиболее ранних патологических изменений, вовлекающих $\alpha$-синуклеин, при введении малой дозы параквата и сопоставить их с симптомами, развивающимися у таких животных на ранней стадии экспериментального паркинсонизма.

\section{МАТЕРИАЛЫ И МЕТОДЫ}

Работу проводили на крысах-самцах линии Wistar $(n=18)$ в возрасте 3-3,5 месяца, которых содержали в виварии при свободном доступе к пище и воде и 12-часовом цикле свет/тьма.

Экспериментальные животные были разделены на две группы: группа «паракват» $(n=10)$ и группа «контроль» $(n=8)$. Крысам первой группы вводили паракват в дозе 6 мг/кг, объемом 0,5 мл. Контрольным животным вводили только физиологический раствор в том же объеме. Токсин растворяли в физиологическом растворе и вводили внутрибрюшинно через день в течение 4 недель. На следующий день после последней инъекции проводили тесты «открытое поле» (ОП) и «сужающаяся дорожка» (СД), которые позволяют оценить нарушения локомоции экспериментальных животных. Исходный уровень двигательной активности был определен у интактных крыс, т. е. до начала введения препаратов. Установка ОП (изготовлена в мастерских ФГБНУ НЦН) представляла собой квадратный короб, со стороной 75 см и высотой 40 см; площадь пола установки разделена на 25 квадратов. При проведении теста оценивали величину пройденного крысой пути за 3 мин. Установка СД (Open science; Россия) представляла собой 2 планки, наложенные друг на друга, длиной 165 см: ширина нижней планки - от 10 до 5,5 см, ширина верхней планки - от 6 до 1,5 см, высота - 2 см. На узком конце дорожки располагается короб (укрытие), имеющий съемную крышку и отверстие в передней панели, через которое животное может проникнуть внутрь. Вся конструкция приподнята над полом на высоту 70 см. Экспериментальное животное должно пройти по верхней планке от начала дорожки до укрытия. Подсчитывали число оступаний (соскальзываний) с верхней планки на нижнюю при проходе по всей длине установки и общее количество шагов каждой конечностью. Регистрацию поведения экспериментальных животных проводили с помощью системы видеонаблюдения Any-maze (Stoelting Inc., США).

Для морфологического исследования было взято по четыре образца мозга животных из групп «контроль» и «паракват». Мозг извлекали и фиксировали 4\%-м раствором формалина. Образцы пропитывали средой O.C.T. (TissueTek; США) и готовили серийные фронтальные срезы толщиной 10 мкм на криостате Tissue-Tek Cryo3 Flex (Sakura Finetek; США). Срезы окрашивали иммунофлуоресцентным методом для выявления тирозингидроксилазы (ТирГд) - маркерного белка дофаминергических волокон и кислого глиофибриллярного белка (GFAP) для оценки нейродегенеративных изменений В нигростриатной дофаминергической системе. Ядра клеток докрашивали DAPI. Для выявления ТирГд использовали поликлональные кроличьи антитела (1 : 500, Sigma; Германия) и соответствующие вторичные антитела 
козы против иммуноглобулинов кролика, меченые флуорохромом CF488 (1 : 500, Sigma; Германия). Для выявления GFAP использовали антитела, меченые флуорохромом Су3 (Sigma; 1 : 80). С каждого мозга на уровне хвостатого ядра и черной субстанции исследовали 5-10 срезов, взятых на разных уровнях по рострокаудальной оси. Срезы изучали под флуоресцентным микроскопом Eclipse NiU (Nikon; Япония). Количественную оценку плотности ТирГд-позитивных волокон проводили, выделяя исследуемые области вручную, при увеличении объектива ×40 в программе ImageJ (Wayne Rasband (NIH); CША) и оценивали среднюю интенсивность флуоресценции (с коррекцией на фоновое окрашивание) ткани в стриатуме.

Участки тощей кишки длиной 5-7 см извлекали, разрезали продольно вдоль брыжейки, промывали физиологическим раствором и расправляли на дне чашки Петри, покрытом парафином. Фиксировали в 4\%-м растворе формалина на фоссратном буфере в течение 3 ч, затем промывали фоссратным буфером $(\mathrm{pH}=7,4)$ и под бинокулярной лупой Wild M7A (Wild Heerbrugg; Германия) при помощи глазного пинцета удаляли слизистую оболочку и подслизистую основу. Полученные тотальные препараты тонкого кишечника, состоящие из кольцевого и продольного мышечных слоев и располагающегося между ними межмышечного нервного сплетения, использовали для проведения иммунофлуоресцентных реакций. Для выявления нервных волокон в энтеральных сплетениях использовали первичные антитела к $\beta$-ІІІ-тубулину, ТирГд и $\alpha$-синуклеину, фосфорилированному по серину-129 ( $\alpha$-Syn-p129), в разведении $1: 250$. Для визуализации связывания использовали вторичные антитела (Sigma; Германия), меченые флуорохромом CF448, в разведении 1 : 100. Препараты исследовали и фотографировали под микроскопом Nikon Eclipse NiU (Nikon; Япония) с цифровой камерой Nikon DS-Qi (Nikon; Япония). Морфометрию выполняли с помощью программы NIS Elements (Nikon;
Япония) на фотоизображениях, полученных при увеличении объектива ×10, исследуя не менее 30-40 полей зрения на животное. В программе NIS Elements оценивали среднюю интенсивность и яркость фрлуоресценции (с коррекцией на фоновое окрашивание) $\beta$-ІІІ-тубулин- и ТирГд-позитивных нервных волокон в межмышечном нервном сплетении.

Анализ полученных данных проводили в программе Statistica 12 (StatSoft; США), используя однофакторный дисперсионный анализ (ANOVA) с последующими апостериорными сравнениями по критерию Фишера и тест Манна-Уитни, различия считали значимыми при $p<0,05$

\section{РЕЗУЛЬТАТЫ ИССЛЕДОВАНИЯ}

Всего за время эксперимента животным было сделано 12 инъекций параквата. Исходная величина пройденного в ОП пути у интактных крыс составила 4,96 \pm 0,7 м. Тестирование поведения на следующий день после последней инъекции показало снижение двигательной активности в ОП у крыс, получавших паракват, однако статистически значимых различий с контролем получено не было (рис. 1).

Тест «СД» выявил нарушения координации у крыс под действием параквата, что выразилось в статистически значимом увеличении числа оступаний левыми конечностями на нижнюю планку дорожки (рис. 2). Число оступаний подсчитывалось в процентах от общего числа шагов соответствующими конечностями.

При исследовании черной субстанции у животных, получавших паракват, выявляли снижение окрашивания на ТирГд и повреждение дофаминергических нейронов, однако наиболее выраженные изменения отмечали в стриатуме. По сравнению с контрольной группой, интенсивность окрашивания стриатума животных на ТирГд статистически значимо снижалась (рис. 3). При этом диффузное снижение плотности выявляемых

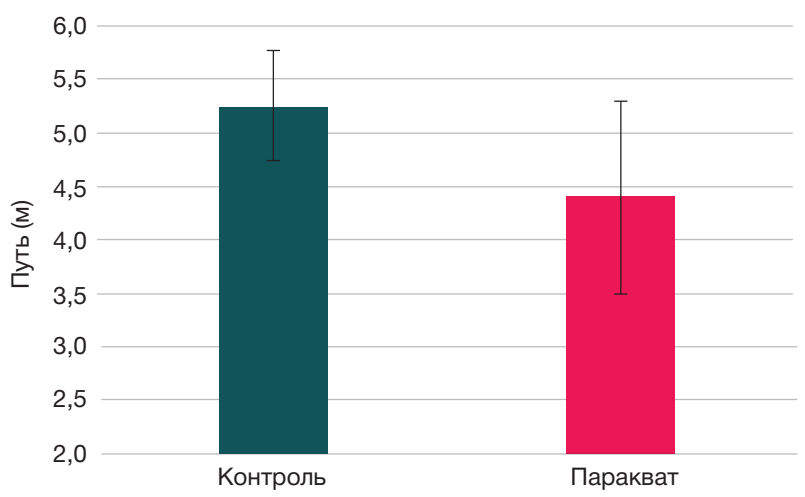

Рис. 1. Длина пробега в открытом поле животных групп «контроль» и «паракват»

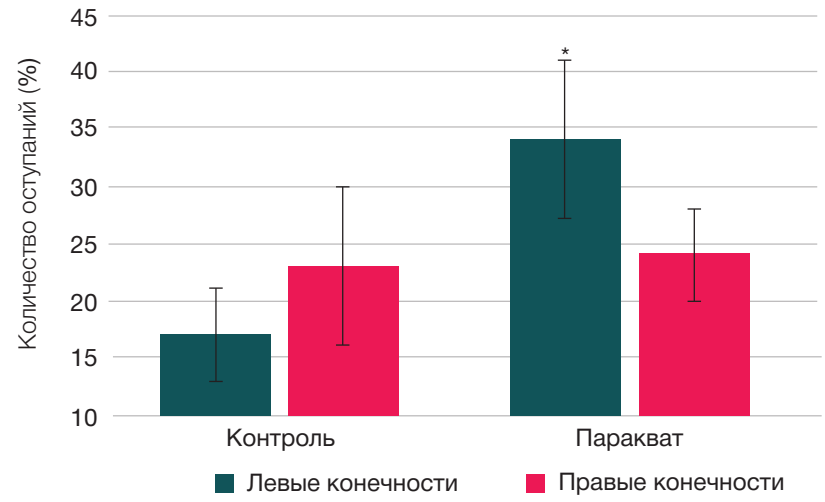

Рис. 2. Количество оступаний (в \% от общего количества шагов) животных групп «контроль» и «паракват» в тесте «сужающаяся дорожка» (* - p = 0,0445) 
дофаминергических волокон отмечали преимущественно в дорсальных отделах стриатума. Кроме того, выявляли умеренный глиоз - гипертрофию отростков GFAPпозитивных астроцитов.

В миентеральном сплетении тонкого кишечника крыс при введении параквата было выявлено снижение интенсивности иммунофрлуоресцентного окрашивания на $\beta$-III-тубулин и ТирГд (рис. 4). Содержание фосфорилированного $\alpha$-синуклеина ( $\alpha$-Syn-p129) увеличивалось в телах миентеральных нейронов и в ТирГд-позитивных волокнах (рис. 5).

\section{ОБСУЖДЕНИЕ РЕЗУЛЬТАТОВ}

Паракват - весьма перспективный токсин для моделирования БП за счет ряда особенностей этого соединения, позволяющих использовать индуцированные им модели при проверке различных гипотез патогенеза БП и тестирования новых препаратов [11]. Согласно литературным данным, введение параквата вызывает в нейронах окислительный стресс, продукцию свободных радикалов in vitro $и$ in vivo, а также повышение уровней $\alpha$-синуклеина и тау-белка с их аккумуляцией $[8,12,13]$. Несмотря на структурное сходство параквата и МФ ${ }^{+}$ [14], проникновение в мозг и механизм действия этих нейротоксинов разные. Оба они представляют собой заряженные молекулы, но паракват, в отличие от МФП+', проникает в мозг с помощью транспортера нейтральных аминокислот $[15,16]$. Данные об эффекте параквата на дофаминергические нейроны довольно противоречивы. В одних работах были показаны нарушения двигательной функции и гибель досаминергических нейронов после системного введения параквата мышам и крысам [14, 10, 17], другие исследователи при использовании параквата не обнаружили изменений моторики животных, несмотря на дегенерацию нигростриатного пути [18, 14]. При этом, индуцируя агрегацию $\alpha$-синуклеина и другие нарушения в дофаминергических нейронах черной субстанции, паракват не оказывает выраженного эффекта на уровень досамина в стриатуме. Возможно, сохранность уровня
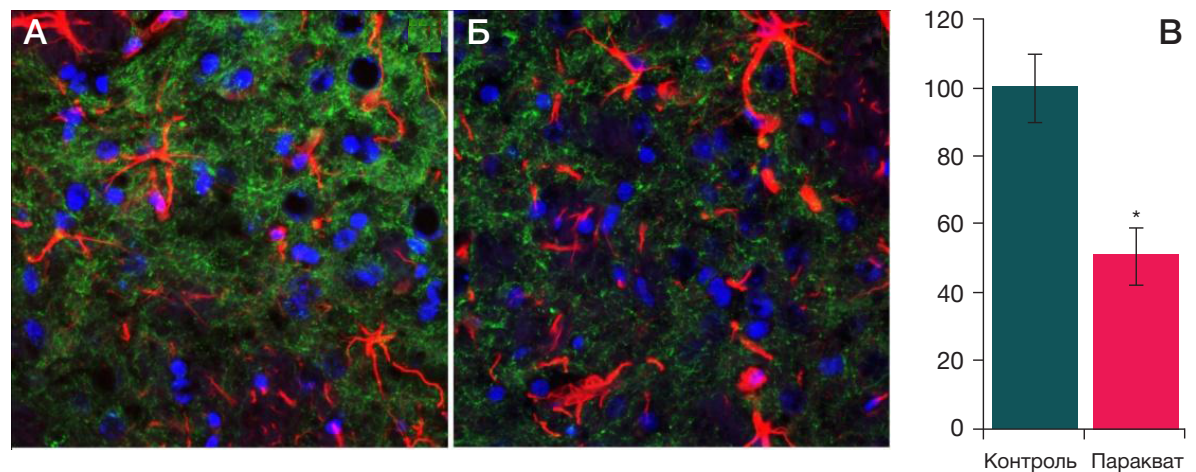

Рис. 3. Изменения в стриатуме экспериментальных животных под действием параквата. Снижение плотности ТирГд-позитивных волокон и гипертрофия астроцитов в стриатуме под действием параквата в группе «контроль» (А), в группе «паракват» (Б). Окраска на ТирГд показана зеленым, GFАР - красным, DAPI - синим. (Иммунофлуоресцентное окрашивание; ув. об. х40). В. Изменения интенсивности окрашивания на ТирГд в \% от интактного контроля (* $-p=0,033 ;$ критерий Манна-Уитни)
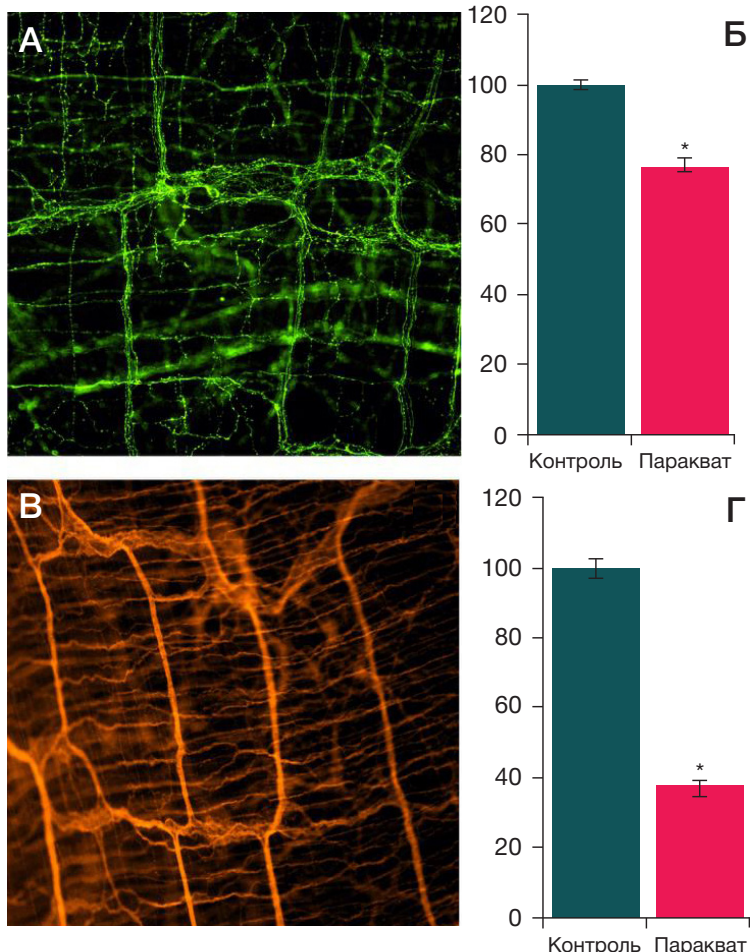

Рис. 4. Морфология нервных волокон миентерального сплетения кишечника крысы, содержащих ТирГд (А) и $\beta$-ІІІ-тубулин (В), и изменения интенсивности окрашивания на ТирГд (Б) и $\beta$-ІІІ-тубулин (Г) в группе, получавшей паракват (\% от контроля; ув. об. $\left.\times 10 ;{ }^{*}-p=0,01\right)$ 

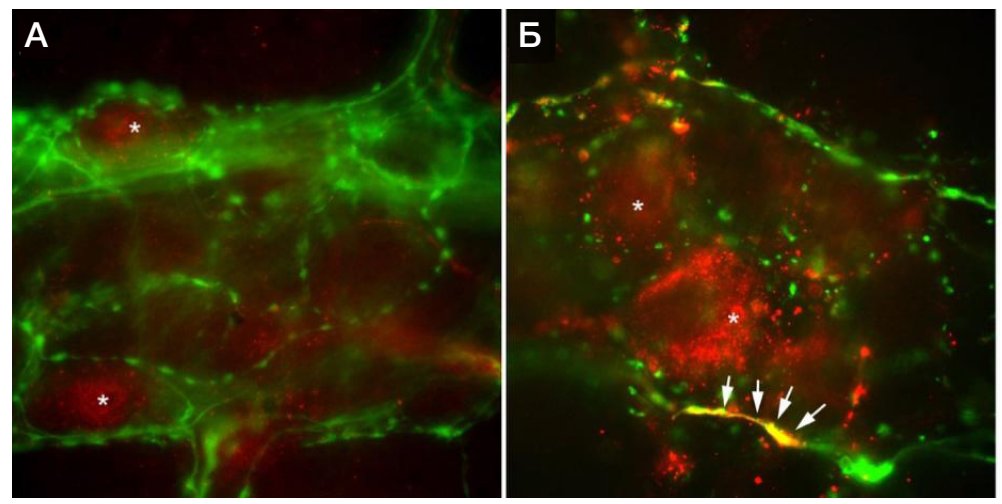

Рис. 5. Локализация $\alpha$-Syn-p129 (показано красным) и ТриГд (показано зеленым) в ганглиях миентерального сплетения у контрольных (А) и получавших паракват (Б) животных. Синуклеин-позитивные включения в содержащем ТриГд волокне показаны стрелками; тела нейронов - звездочками (*) (ув. об. х40)

дофамина в этой модели обусловлена компенсаторным повышением активности ТирГд в стриатуме [19].

Для моделирования БП у крыс чаще всего используют введение параквата, растворенного в физиологическом растворе, в дозе 10 мг/кг. Показано, что такой режим введения параквата внутрибрюшинно в течение 3 недель вызывает селективную гибель дофаминергических нейронов в черной субстанции, снижение двигательной координации, тонуса и сократительной способности мышц [10]. Более высокие дозы параквата (20-25 мг/кг) используют для моделирования тяжелых повреждений внутренних органов, в частности, почек и легочной ткани [20]. Однако наш предшествующий опыт применения параквата в дозе 10 мг/кг для моделирования БП на крысах вышеуказанной линии и возраста оказался негативным, к 5-й инъекции все животные $(n=10)$ погибли, а при патологоанатомическом исследовании погибших животных были обнаружены характерные для действия параквата изменения в легочной и почечной тканях и тканях других висцеральных органов [20]. Использование в настоящей работе дозы параквата 6 мг/кг позволило избежать гибели животных и в то же время воспроизвести поведенческие и морфохимические нарушения, имитирующие симптомы начальной стадии БП, включая типичную асимметрию двигательных нарушений. Латерализацию двигательных симптомов при БП (гипокинезии, тремора покоя и др.) отмечают уже в дебюте заболевания, и она может становиться менее выраженной по мере его прогрессирования [21]. Моторная асимметрия имеет большую клиническую значимость для диффференциальной диагностики БП и других сходных паркинсонических синдромов. Вместе с тем, асимметрия повреждения нейронов черной субстанции у людей с БП продемонстрирована лишь в немногих работах [22, 21], а моделей, воспроизводящих односторонние двигательные нарушения при системном введении нейротоксинов, практически не описано. Проведенное нами исследование восполняет этот пробел.

В миентеральном сплетении интенсивность окрашивания $\beta$-III-тубулин-позитивных нервных волокон под действием параквата снижалась относительно контроля. Хотя нарушение сборки микротрубочек под влиянием параквата [23] было описано ранее, полученные нами данные о снижении окрашивания на $\beta$-ІІІ-тубулин вступают в противоречие с результатами некоторых других исследователей [6]. По-видимому, выявленные изменения могут отражать не столько снижение абсолютного числа тубулин-позитивных нервных волокон, сколько изменение морфологии сети энтеральной нервной системы, т. е. ее разрежение.
В исследованном материале мы не выявили тел нейронов, содержащих ТирГд; полученные результаты свидетельствуют о том, что ТирГд-позитивные волокна в межмышечном сплетении являются симпатическими афферентами, и это согласуется с данными других авторов $[24,25]$. Интенсивность окрашивания на ТирГд под действием параквата также снижалась относительно контроля, что может свидетельствовать о повреждении симпатической иннервации тонкого кишечника. Кроме этого, такое снижение могло быть вызвано не только изменением плотности волокон, но и изменением функционального состояния нейронов.

$\alpha$-Синуклеин в структурах периферической вегетативной нервной системы был выявлен нами как у экспериментальных, так и у контрольных животных. Известно, что часть $\alpha$-синуклеина в нормальных условиях находится в нейронах в фоссорилированной форме [26]. Этот белок локализовался диффузно в соме части нейронов миентеральных ганглиев. В то же время у животных, получавших паракват, было обнаружено усиление окрашивания тел нейронов и утолщение ТирГд-позитивных нервных волокон, иммунопозитивных к фосфорилированной форме $\alpha$-синуклеина ( $\alpha$-Syn-p129). Изменения морфологии нервных волокон и накопление $\alpha$-Syn-p129 может свидетельствовать об образовании специфичных для БП белковых агрегатов под действием параквата. Увеличение экспрессии $\alpha$-синуклеина в нейронах черной субстанции под действием параквата, показанное ранее [6], вместе с результатами нашей работы подчеркивает сходство молекулярного патогенеза данной модели паркинсонизма с механизмами развития БП у человека.

Вероятными причинами накопления $\alpha$-синуклеина в энтеральной нервной системе при воздействии параквата являются продукция АФК и воспаление [27]. Показано, что воспалительные заболевания кишечника у приматов вызывают накопление фоссрорилированного $\alpha$-синуклеина в нейронах миентеральных ганглиев [28]. Нарушение баланса между фосфорилированным и нефосфорилированным пулами $\alpha$-синуклеина сопровождают образование токсических фибрилл белка и формирование его нерастворимых агрегатов [29]. Патологическое накопление $\alpha$-синуклеина в волокнах, иннервирующих желудочнокишечный тракт, и энтеральных ганглиях, характерное для ранних стадий БП, рассматривают как потенциальный биомаркер заболевания [30].

\section{ВЫВОДЫ}

Системное введение параквата в дозе 6 мг/кг вызывало поведенческие и морфохимические изменения, сходные 
с таковыми у пациентов на ранней стадии БП, включая ключевое звено патогенеза - $\alpha$-синуклеиновую патологию в структурах периферической вегетативной нервной системы. Такой режим введения параквата представляется чрезвычайно перспективным в моделировании БП и имеет большое значение для лучшего понимания патогенеза заболевания и разработки новых терапевтических стратегий.

\section{Литература}

1. Pringsheim T, Jette N, Frolkis A, Steeves TD. The prevalence of Parkinson's disease: a systematic review and meta-analysis. Mov Disord. 2014; (29): 1583-90.

2. Poewe W, Seppi K, Tanner CM, Halliday GM, Brundin P, Volkmann J, et al. Parkinson disease. Nat Rev Dis Primers. 2017; (3): 17013.

3. Chaudhuri K Ray, Titova N, editors. Nonmotor Parkinson's: The hidden face. International Review of Neurology. Vol. 133. Academic Press, 2017; 794 p.

4. Иллариошкин С. Н. Современные представления об этиологии болезни Паркинсона. Неврологический журнал. 2015; (4): 4-13.

5. Jellinger KA. Synuclein deposition and non-motor symptoms in Parkinson disease. J Neurol Sci. 2011; (310): 107-11.

6. Manning-Bog A, Mccormack A, Li J, Uversky V, Fink A, Di Monte D. The herbicide paraquat causes up-regulation and aggregation of alpha-synuclein in mice: paraquat and alpha-synuclein. J Biol Chem. 2002; (277): 1641-4.

7. Moretto A, Colosio C. Biochemical and toxicological evidence of neurological effects of pesticides: the example of Parkinson's disease. Neurotoxicology. 2011; (32): 383-91.

8. Fernagut PO, Hutson CB, Fleming SM, Tetreaut NA, Salcedo J, Masliah E, et al. Behavioral and histopathological consequences of paraquat intoxication in mice: Effects of alpha-synuclein overexpression. Synapse. 2007; (61): 991-1001.

9. Mak SK, McCormack AL, Manning-Bog AB, Cuervo AM, Di Monte DA. Lysosomal degradation of alpha-synuclein in vivo. J Biol Chem. 2010; (285): 13621-9.

10. Fahimi MA. Shechab S, Nemmar A, Adem A, Dhanasekaran S, Hasan MY. Daily Subacute Paraquat Exposure Decreases Muscle Function and Substantia Nigra Dopamine Level Physiol Res. 2013; (62): 313-21.

11. Tieu K. A Guide to Neurotoxic Animal Models of Parkinson's Disease Cold Spring Harb Perspect Med. 2011; (1): a009316.

12. Bus JS, Gibson JE. Paraquat: Model for Oxidant-Initiated Toxicity. Environ Health Perspect. 1984; (55): 37-46.

13. Wills J, Credle J, Oaks AW, Duka V, Lee JH, Jones J. et al Paraquat, but Not Maneb, Induces Synucleinopathy and Tauopathy in Striata of Mice through Inhibition of Proteasomal and Autophagic Pathways. PLoS ONE. 2012; 7(1): 1-12. DOI: 10.1371/journal. pone.0030745

14. McCormack AL, Thiruchelvam M, Manning-Bog AB, Thiffault C Langston JW, Cory-Slechta DA, et al. Environmental risk factors and Parkinson's disease: Selective degeneration of nigral dopaminergic neurons caused by the herbicide paraquat. Neurobiol Dis. 2002; (10): 119-27.

15. Shimizu K, Ohtaki K, Matsubara K, Aoyama K, Uezono T, Saito O, et al. Carrier-mediated processes in blood - brain barrier penetration and neural uptake of paraquat. Brain Res. 2001; (906): 135-42.

16. McCormack AL, Di Monte DA. Effects of L-dopa and other amino acids against paraquat-induced nigrostriatal degeneration. J Neurochem. 2003; (85): 82-6.

17. Izumi Y, Ezumi M, Takada-Takatori Y, Akaike A, Kume T. Endogenous
Dopamine Is Involved in the Herbicide Paraquat-Induced Dopaminergic Cell Death Toxicological Sciences. 2014; 139 (2): 466-78

18. Thiruchelvam M, Brockel BJ, Richfield EK, Baggs RB, CorySlechta DA. Potentiated and preferential effects of combined paraquat and maneb on nigrostriatal dopamine systems: Environmental risk factors for Parkinson's disease? Brain Res. 2000; (873): 225-34

19. Ossowska K, Wardas J, Smialowska M, Kuter K, Lenda T, Wieronska JM, et al. A slowly developing dysfunction of dopaminergic nigrostriatal neurons induced by long-term paraquat administration in rats: An animal model of pre-clinical stages of Parkinson's disease? Eur J Neurosci. 2005; (22): 1294-304.

20. Junboa Z, Yongtaob Y, Hongboa Li, Fenshuanga Z, Ruyuna L, Chun'aia $Y$. Experimental study of sucralfate intervention for paraquat poisoning in rats. Environmental Toxicology and Pharmacology. 2017; (53): 57-63.

21. Riederer $P$, Jellinger KA, Kolber P, Hipp G, Sian-Hulsmann J, Kruger R. Lateralisation in Parkinson disease. Cell Tissue Res. 2018; (373): 297. https://doi.org/10.1007/s00441-018-2832-z.

22. Djaldetti R, Ziv I, Melamed E. The mystery of motor asymmetry in Parkinson's disease. The Lancet Neurology. 2006; 5 (9): 796-802. DOI: 10.1016/s1474-4422(06)70549-x

23. Li WD, Zhao YZ, Chou IN. Paraquat-induced cytoskeletal injury in cultured cells. Toxicol Appl Pharmacol. 1987; 91 (1): 96-106.

24. Phillips RJ, Pairitz JC, Powley TL. Age-related neuronal loss in the submucosal plexus of the colon of Fischer 344 rats. Neurobio Aging. 2007; 28 (7): 1124-37.

25. Phillips RJ, Hudson CN, Powley TL. Sympathetic axonopathies and hyperinnervation in the small intestine smooth muscle of aged Fischer 344 rats. Auton Neurosci. 2013; 179 (1-2): 108-121. DOI: 10.1016/j.autneu.2013.09.002

26. Muntané G, Ferrer I, Martinez-Vicente M. $\alpha$-Synuclein phosphorylation and truncation are normal events in the adult human brain. Neuroscience. 2012; (200): 106-19. DOI: 10.1016/j. neuroscience.2011.10.042

27. Toygar M, Aydin I, Agilli M, Aydin FN, Oztosun M, Gul H, et al. The relation between oxidative stress, inflammation, and neopterin in the paraquat-induced lung toxicity. Hum Exp Toxicol. 2015: 34 (2): 198-204. DOI: 10.1177/0960327114533808.

28. Resnikoff H, Metzger JM, Lopez M, Bondarenko V, Mejia A, Simmons HA, et al. Colonic inflammation affects myenteric alpha-synuclein in nonhuman primates. J Inflamm Res. 2019; (12): 113-26. DOI: 10.2147/JIR.S196552.

29. Zhang J, Li X, Li JD. The Roles of Post-translational Modifications on $\alpha$-Synuclein in the Pathogenesis of Parkinson's Diseases. Front Neurosci. 2019; (13): 381. DOI: 10.3389/fnins.2019.00381.

30. Yan F, Chen Y, Li M, Wang Y, Zhang W, Chen X, et al. Gastrointestinal nervous system $\alpha$-synuclein as a potential biomarker of Parkinson disease. Medicine (Baltimore). 2018; 97 (28): e11337. DOI:10.1097/ MD.0000000000011337.

\section{References}

1. Pringsheim T, Jette N, Frolkis A, Steeves TD. The prevalence of Parkinson's disease: a systematic review and meta-analysis. Mov Disord. 2014; (29): 1583-90.

2. Poewe W, Seppi K, Tanner CM, Halliday GM, Brundin P, Volkmann J, et al. Parkinson disease. Nat Rev Dis Primers. 2017; (3): 17013.

3. Chaudhuri K Ray, Titova N, editors. Nonmotor Parkinson's: The hidden face. International Review of Neurology. Vol. 133.

Academic Press, 2017; 794 p

4. Illarioshkin SN. Sovremennye predstavleniya ob etiologii bolezni Parkinsona. Nevrologicheskiy zhurnal. 2015; (4): 4-13.

5. Jellinger KA. Synuclein deposition and non-motor symptoms in Parkinson disease. J Neurol Sci. 2011; (310): 107-11.

6. Manning-Bog A, Mccormack A, Li J, Uversky V, Fink A, Di Monte D. The herbicide paraquat causes up-regulation and aggregation 
of alpha-synuclein in mice: paraquat and alpha-synuclein. J Biol Chem. 2002; (277): 1641-4.

7. Moretto A, Colosio C. Biochemical and toxicological evidence of neurological effects of pesticides: the example of Parkinson's disease. Neurotoxicology. 2011; (32): 383-91.

8. Fernagut PO, Hutson CB, Fleming SM, Tetreaut NA, Salcedo J, Masliah E, et al. Behavioral and histopathological consequences of paraquat intoxication in mice: Effects of alpha-synuclein overexpression. Synapse. 2007; (61): 991-1001.

9. Mak SK, McCormack AL, Manning-Bog AB, Cuervo AM, Di Monte DA. Lysosomal degradation of alpha-synuclein in vivo. $J$ Biol Chem. 2010; (285): 13621-9.

10. Fahimi MA. Shechab S, Nemmar A, Adem A, Dhanasekaran S, Hasan MY. Daily Subacute Paraquat Exposure Decreases Muscle Function and Substantia Nigra Dopamine Level Physiol Res. 2013; (62): 313-21.

11. Tieu K. A Guide to Neurotoxic Animal Models of Parkinson's Disease Cold Spring Harb Perspect Med. 2011; (1): a009316.

12. Bus JS, Gibson JE. Paraquat: Model for Oxidant-Initiated Toxicity. Environ Health Perspect. 1984; (55): 37-46.

13. Wills J, Credle J, Oaks AW, Duka V, Lee JH, Jones J, et al. Paraquat, but Not Maneb, Induces Synucleinopathy and Tauopathy in Striata of Mice through Inhibition of Proteasomal and Autophagic Pathways. PLoS ONE. 2012; 7(1): 1-12. DOI: 10.1371/journal. pone.0030745

14. McCormack AL, Thiruchelvam M, Manning-Bog AB, Thiffault $C$, Langston JW, Cory-Slechta DA, et al. Environmental risk factors and Parkinson's disease: Selective degeneration of nigral dopaminergic neurons caused by the herbicide paraquat. Neurobiol Dis. 2002; 10: 119-27.

15. Shimizu K, Ohtaki K, Matsubara K, Aoyama K, Uezono T, Saito O, et al. Carrier-mediated processes in blood - brain barrier penetration and neural uptake of paraquat. Brain Res. 2001; (906): 135-42.

16. McCormack AL, Di Monte DA. Effects of L-dopa and other amino acids against paraquat-induced nigrostriatal degeneration. $J$ Neurochem. 2003; (85): 82-6.

17. Izumi Y, Ezumi M, Takada-Takatori Y, Akaike A, Kume T. Endogenous Dopamine Is Involved in the Herbicide Paraquat-Induced Dopaminergic Cell Death Toxicological Sciences. 2014; 139 (2): 466-78.

18. Thiruchelvam M, Brockel BJ, Richfield EK, Baggs RB, CorySlechta DA. Potentiated and preferential effects of combined paraquat and maneb on nigrostriatal dopamine systems: Environmental risk factors for Parkinson's disease? Brain Res.
2000; (873): 225-34.

19. Ossowska K, Wardas J, Smialowska M, Kuter K, Lenda T, Wieronska JM, et al. A slowly developing dysfunction of dopaminergic nigrostriatal neurons induced by long-term paraquat administration in rats: An animal model of pre-clinical stages of Parkinson's disease? Eur J Neurosci. 2005; (22): 1294-304.

20. Junboa Z, Yongtaob Y, Hongboa Li, Fenshuanga Z, Ruyuna L, Chun'aia Y. Experimental study of sucralfate intervention for paraquat poisoning in rats. Environmental Toxicology and Pharmacology. 2017; (53): 57-63.

21. Riederer P, Jellinger KA, Kolber P, Hipp G, Sian-Hulsmann J, Kruger R. Lateralisation in Parkinson disease. Cell Tissue Res. 2018; (373): 297. https://doi.org/10.1007/s00441-018-2832-z.

22. Djaldetti R, Ziv I, Melamed E. The mystery of motor asymmetry in Parkinson's disease. The Lancet Neurology. 2006; 5 (9): 796-802. DOI: 10.1016/s1474-4422(06)70549-x

23. Li WD, Zhao YZ, Chou IN. Paraquat-induced cytoskeletal injury in cultured cells. Toxicol Appl Pharmacol. 1987; 91 (1): 96-106.

24. Phillips RJ, Pairitz JC, Powley TL. Age-related neuronal loss in the submucosal plexus of the colon of Fischer 344 rats. Neurobiol Aging. 2007; 28 (7): 1124-37.

25. Phillips RJ, Hudson CN, Powley TL. Sympathetic axonopathies and hyperinnervation in the small intestine smooth muscle of aged Fischer 344 rats. Auton Neurosci. 2013; 179 (1-2): 108-121. DOI: 10.1016/j.autneu.2013.09.002

26. Muntané G, Ferrer I, Martinez-Vicente M. $\alpha$-Synuclein phosphorylation and truncation are normal events in the adult human brain. Neuroscience. 2012; (200): 106-19. DOI: 10.1016/j. neuroscience.2011.10.042.

27. Toygar M, Aydin I, Agilli M, Aydin FN, Oztosun M, Gul H, et al. The relation between oxidative stress, inflammation, and neopterin in the paraquat-induced lung toxicity. Hum Exp Toxicol. 2015; 34 (2): 198-204. DOI: 10.1177/0960327114533808.

28. Resnikoff $\mathrm{H}$, Metzger JM, Lopez M, Bondarenko V, Mejia A, Simmons HA, et al. Colonic inflammation affects myenteric alpha-synuclein in nonhuman primates. J Inflamm Res. 2019; (12): 113-26. DOI: 10.2147/JIR.S196552.

29. Zhang J, Li X, Li JD. The Roles of Post-translational Modifications on $\alpha$-Synuclein in the Pathogenesis of Parkinson's Diseases. Front Neurosci. 2019; (13): 381. DOI: 10.3389/fnins.2019.00381.

30. Yan F, Chen Y, Li M, Wang Y, Zhang W, Chen X, et al. Gastrointestinal nervous system $\alpha$-synuclein as a potential biomarker of Parkinson disease. Medicine (Baltimore). 2018; 97 (28): e11337. DOI:10.1097/ MD.0000000000011337. 